\title{
BMJ Open Using a Delphi process to define priorities for prison health research in Canada
}

Fiona G Kouyoumdjian, ${ }^{1}$ Andrée Schuler, ${ }^{1}$ Kathryn E Mclsaac, ${ }^{1,2}$ Lucie Pivnick, ${ }^{3}$
Flora I Matheson, ${ }^{1}$ Glenn Brown, ${ }^{4}$ Lori Kiefer, ${ }^{2,5}$ Diego Silva, ${ }^{1,6}$ Stephen W Hwang ${ }^{1}$

To cite: Kouyoumdjian FG, Schuler A, Mclsaac KE, et al. Using a Delphi process to define priorities for prison health research in Canada. BMJ Open 2016;6:e010125. doi:10.1136/bmjopen-2015010125

- Prepublication history for this paper is available online. To view these files please visit the journal online (http://dx.doi.org/10.1136/ bmjopen-2015-010125).

Received 30 September 2015 Revised 1 December 2015 Accepted 23 December 2015

\section{CrossMark}

${ }^{1}$ Centre for Research on Inner City Health, St. Michael's Hospital, Toronto, Ontario, Canada

${ }^{2}$ Dalla Lana School of Public Health, Toronto, Ontario, Canada

${ }^{3}$ Faculty of Medicine, McMaster University, Hamilton, Ontario, Canada

${ }^{4}$ Department of Family Medicine, Queen's University, Kingston, Ontario, Canada

${ }^{5}$ Ontario Ministry of

Community Safety and

Correctional Services,

Toronto, Ontario, Canada

${ }^{6}$ Faculty of Health Sciences,

Simon Fraser University,

Burnaby, British Columbia, Canada

Correspondence to Dr Fiona G Kouyoumdjian; kouyoumdjiaf@smh.ca

\section{ABSTRACT}

Objectives: A large number of Canadians spend time in correctional facilities each year, and they are likely to have poor health compared to the general population. Relatively little health research has been conducted in Canada with a focus on people who experience detention or incarceration. We aimed to conduct a Delphi process with key stakeholders to define priorities for research in prison health in Canada for the next 10 years.

Setting: We conducted a Delphi process using an online survey with two rounds in 2014 and 2015.

Participants: We invited key stakeholders in prison health research in Canada to participate, which we defined as persons who had published research on prison health in Canada since 1994 and persons in the investigators' professional networks. We invited 143 persons to participate in the first round and 59 participated. We invited 137 persons to participate in the second round and 67 participated.

\section{Primary and secondary outcome measures:}

Participants suggested topics in the first round, and these topics were collated by investigators. We measured the level of agreement among participants that each collated topic was a priority for prison health research in Canada for the next 10 years, and defined priorities based on the level of agreement.

Results: In the first round, participants suggested 71 topics. In the second round, consensus was achieved that a large number of suggested topics were research priorities. Top priorities were diversion and alternatives to incarceration, social and community re-integration, creating healthy environments in prisons, healthcare in custody, continuity of healthcare, substance use disorders and the health of Aboriginal persons in custody.

Conclusions: Generated in an inclusive and systematic process, these findings should inform future research efforts to improve the health and healthcare of people who experience detention and incarceration in Canada.

\section{INTRODUCTION}

Worldwide, more than 11 million people are incarcerated at any given time, ${ }^{1}$ and an estimated 30 million people move through the

\section{Strengths and limitations of this study}

- Participants represented diverse geographical areas, types of work and work settings relevant to prison health research in Canada.

- Several investigators collated topics identified in the first round to capture breadth and specificity.

- Some collated topics are broad and contain multiple components, which means that translating priorities into research plans will require further consideration and consultation.

- Stopping the Delphi process after the second round precluded us from determining whether stability had been achieved regarding whether each topic was a priority and the relative priority of suggested topics, however, we decided to stop the process given the high level of consensus achieved for so many topics.

prison system annually. ${ }^{2}$ In Canada, there are approximately 251629 adult admissions to provincial and territorial facilities and 8006 to federal facilities over a year, ${ }^{3}$ and an average of 40000 people in correctional facilities on any given day. ${ }^{1}$ This translates into an estimated 1 in 250 people in Canada who are admitted to a correctional facility each year.

Substantial international evidence reveals that people who experience detention or incarceration have poor health compared with the general population, as indicated by the prevalence of mental illness, infectious disease, chronic disease, injury and mortality. ${ }^{4}$ In Canada, there is a paucity of research on the health of people who experience detention or incarceration. ${ }^{5}$ Research has the potential to identify ways to improve health in this population. ${ }^{6}$ In the context of much need and little research to date, efforts are needed to define priorities for research. ${ }^{7}$

We conducted a Delphi process with key stakeholders to define priorities for research in prison health in Canada for the next 10 years. 


\section{METHODS}

\section{Participants}

We invited persons to participate who had published research on prison health in Canada since 1994, as identified in a scoping review, ${ }^{5}$ or persons who were knowledgeable about and interested in prison health research who were in the professional networks of the study investigators. These persons included researchers, persons working in federal and provincial government agencies, persons working in non-governmental organisations and persons with a history of detention or incarceration in provincial or federal facilities in Canada.

\section{Delphi process}

The Delphi method is an iterative process in which a facilitator leads a group of experts to achieve consensus on a given topic, ${ }^{8-11}$ and involves conducting surveys anonymously with individuals to collect data, collating data, presenting results back to the group and having participants reassess their responses in light of group responses. The steps of collating and presenting data and the completion of surveys continue until consensus is achieved, and each of these steps is considered a 'round.'

In December 2014, we emailed potential participants to provide information about the study, to invite them to participate in the first round, and to provide a link to an online survey. In the first round survey, we asked participants to specify the province and organisation in which they work and to list 5-10 research priorities for prison health research in Canada for the next 10 years. We specified that we were using the term prison health broadly to include persons in federal and provincial facilities, persons who are remanded (ie, detained in custody prior to sentencing) or sentenced, and also persons who have been released from custody.

Three investigators collated the first round responses through an iterative process in which we independently developed categories to group responses into broad topic areas, compared and came to consensus on categories and then grouped similar responses within categories into topics. In the second round in May 2015, we asked participants to provide information about the province and organisation in which they work, and to indicate whether they agreed that each collated topic was a priority by indicating one of five options on a Likert scale: strongly agree, agree, neither agree nor disagree, disagree, strongly disagree. ${ }^{9}$

We decided a priori to stop conducting rounds if participants reached consensus regarding whether each topic is a priority, or once we had conducted three rounds. ${ }^{89}$ We defined consensus a priori as more than $70 \%$ of participants indicating that they strongly agreed or agreed that the topic was a priority or that they disagreed or strongly disagreed that the topic was a priority, respectively. ${ }^{8}$

We obtained consent from participants, with completion of the online survey indicating consent, which was approved by the Research Ethics Board. The
Correctional Service of Canada (CSC) reviewed the study protocol and in May of 2015 approved one senior employee to participate as a representative of the organisation.

\section{RESULTS}

For the first round, we invited 143 persons to participate: 106 persons who had published in this field and 37 persons in the investigators' professional networks. Fifty-nine persons participated, and characteristics of their work are shown in table 1 . Almost half of participants were from Ontario, more than half worked primarily as researchers and over $40 \%$ worked in a university setting. Most regions of Canada were represented and participants reported doing a variety of types of work and working in different settings. Participants suggested 410 topics, which we collated into 71 discrete priorities, shown in table 2.

For the second round, we invited 137 persons to participate: 99 persons who had published in this field (excluding six persons who declined participation and one for whom the contact information no longer worked) and 38 persons in the investigators' professional networks (including the CSC representative). Sixty-seven

Table 1 Characteristics of participants in rounds one and two of a Delphi process in 2015 to define priorities for prison health research in Canada in the next 10 years

\begin{tabular}{|c|c|c|}
\hline & $\begin{array}{l}\text { Round } 1 \\
(\mathrm{~N}=59) \\
\text { n (\%) }\end{array}$ & $\begin{array}{l}\text { Round } 2 \\
(\mathrm{~N}=67), \\
\text { n (\%) }\end{array}$ \\
\hline \multicolumn{3}{|c|}{ Geographical area where work is based } \\
\hline Ontario & $29(49.2)$ & $33(49.3)$ \\
\hline British Columbia & $10(16.9)$ & $14(20.9)$ \\
\hline Quebec & $5(8.5)$ & $5(7.5)$ \\
\hline $\begin{array}{l}\text { Saskatchewan, Alberta, } \\
\text { Manitoba* }\end{array}$ & $4(6.8)$ & $6(9.0)$ \\
\hline $\begin{array}{l}\text { Nova Scotia, New Brunswick, } \\
\text { Prince Edward Island* }\end{array}$ & $3(5.1)$ & $3(4.5)$ \\
\hline National/federal & $4(6.8)$ & $4(6.0)$ \\
\hline Other & $4(6.8)$ & $2(3.0)$ \\
\hline \multicolumn{3}{|c|}{ Type of work carried out most of the time } \\
\hline Research & $33(55.9)$ & $39(58.2)$ \\
\hline Policy work & 7 (11.9) & $6(9.0)$ \\
\hline Clinical work & $5(8.5)$ & $6(9.0)$ \\
\hline Health care management & $3(5.1)$ & $2(3.0)$ \\
\hline Advocacy & $2(3.4)$ & $2(3.0)$ \\
\hline Other & $9(15.3)$ & $10(14.9)$ \\
\hline Not specified & $0(0)$ & $2(3.0)$ \\
\hline \multicolumn{3}{|c|}{ Setting in which most work carried out } \\
\hline University & $25(42.4)$ & $36(53.7)$ \\
\hline Non-governmental organisation & $10(16.9)$ & $9(13.4)$ \\
\hline Federal government & 8 (13.6) & $6(9.0)$ \\
\hline Provincial government & $3(5.1)$ & $5(7.5)$ \\
\hline Correctional facility & $2(3.4)$ & $2(3.0)$ \\
\hline Other & $11(18.6)$ & $9(13.4)$ \\
\hline
\end{tabular}

*These provinces were grouped to prevent the identification of individual participants. 
Table 2 Collated topics suggested in first round of a Delphi process in 2015 as priorities for prison health research in Canada, $\mathrm{N}=59$ participants

\section{Category}

Prevention of detention/ incarceration

\section{Conditions in custody}

Healthcare in custody

Reintegration and continuity of care

General health status

Social determinants of health

Mental health

\section{Topic}

Diversion and alternatives to incarceration, including for persons who use drugs and persons with mental illness, use of drug courts and addictions treatment, sentence length (mandatory minimum sentences)

Supporting youth at risk of criminal justice involvement, including youth with behavioural problems from trauma, early substance use, etc

Reducing recidivism, including assessing risk factors for recidivism, and how health professionals can reduce risk

Access to harm reduction tools and supports, including needle exchange

Staffing of correctional facilities, including staff training on mental health, healthcare staffing (24 $\mathrm{h}$ nursing)

Health effects of overcrowding, including on communicable disease transmission

Creating healthy environments in prisons, including trauma-informed environments, disability accommodation, programmes to enhance quality of life, personal safety and cultural safety, exercise and nutrition, effects of smoking ban

Segregation: predictors of use, health effects of and alternatives to segregation

Approach to offender rehabilitation: risk-needs-responsivity verses 'good lives'

Treatment of prisoners/detainees by correctional staff, including use of force, restraints and OC/pepper spray

Confidentiality

value of accreditation of correctional facilities

Access to and quality of healthcare in custody, including mental healthcare, prenatal care, emergency care, preventive care, palliative care, dental care, geriatric medicine, pain management and contraception

Effective case management and individualised treatment programmes in custody Health education/health promotion, including for mental health

Medications in custody: use, management (including forced withdrawal on admission), adherence (including off-label use), availability on formulary and alternatives to pharmacological therapies

Challenges for healthcare providers in corrections: moral distress, perceptions and values Responsivity factors, that is, factors that impact on or enhance an offender's ability to successfully undertake a programme, such as fetal alcohol spectrum disorder or brain injury Risk assessments and actuarial tools, including for women and Aboriginal persons Release/discharge planning, including the effect of planning on recidivism, dealing with pre-release anxiety Continuity of healthcare at the time of admission to and release from custody, including communication of health information and medication adherence and including for persons with mental illness

Social and community reintegration, including for persons with mental illness Developing partnerships between correctional facilities and community organisations Access to healthcare and other services after release from custody, including primary care Health and health service outcomes after release

Health trajectories of people in custody, including biological vs chronological age, health effects of incarceration

Association between health and outcomes, including behaviour in custody, rehabilitation and recidivism

Mortality: rates, causes and prevention, including use of data linkage studies

Obesity

Access to employment and education opportunities, including training

Housing after release

Early childhood: relevance to criminal history and treatment, association between investment in early child development and parenting programmes and incarceration rates

Building healthy relationships including with family and children, buildings skills in parenting, coping, anger management and conflict resolution

Mental disorders: screening, prevalence, comorbidities, etc including bipolar and unipolar depression, schizophrenia, post-traumatic stress disorder, gambling disorder and fetal alcohol spectrum disorder 
Table 2 Continued

Mental health, continued

Substance use and abuse

Chronic diseases Infectious diseases

Injury

\section{Subpopulations}

Methodological approaches

Research ethics

\section{Topic}

Interventions to address mental health issues, including risk management techniques, sex offender treatment, psychopathy treatment, Intermediate Mental Health Care and role of multidisciplinary teams

Substance use disorders, including access to and outcomes of treatment in custody and after release, including in Aboriginal persons, women, parents and pregnant women

Non-abstinence-based substance abuse treatment approaches, including substitution

therapies for opiates, such as methadone

Overdose prevention training and naloxone distribution before release

Drug interdiction strategies: effectiveness

Prescription drug abuse

Illegal drug use in correctional facilities, including injection drug use

Chronic diseases: prevention, prevalence and management, including diabetes

Infection prevention and control in correctional facilities (including testing electric razors pre and postcleaning), including surveillance

HIV: Prevention, epidemiology and treatment, including treatment regimens, adherence and outcomes compared to community

Hepatitis C: Epidemiology, prevention, natural history (does it suppress immune function?)

and treatment

Tuberculosis: Using DNA fingerprinting to identify clusters of tuberculosis cases in persons currently or previously in correctional facilities

Predictors of recurrent MRSA infections

Prevention and treatment of sexually transmitted infections

Self-harm/self-injury: identification and management

Suicide prevention and epidemiology

Injury prevention at the time of release

Brain injury, including association with crime

Health of Aboriginal persons in custody, including mental health and Aboriginal treatment models

Abuse survivors, including survivors of residential schools

Health issues for aging persons in custody, including compassionate release

Women in custody, including supporting women's voices and empowerment

Gender and sexuality issues, including lesbian, gay, bisexual and transgender health

Support for incarcerated mothers and their newborn children, including mother-baby units

Gangs

Juveniles in custody and serving orders in the community

Collaborations between legal and health research

Participatory research

Economic analyses of health, social and offending outcomes after release from custody Interventions research and implementation, including animal-assisted interventions, peer-based interventions, psychologist vs correctional officer-administered interventions and community-based interventions

Longitudinal studies of persons from the time in custody to long after release

Multijurisdictional studies to compare outcomes across provinces/territories

Policy research on professional and jurisdictional issues in the delivery of health services in custody

Population-wide studies or representative samples, that is, research that is not limited to subgroups

Theoretical medical research on health and justice

Access to participate in research while in custody

Ability to give consent while in custody

MRSA, methicillin-resistant Staphylococcus aureus; OC, oleoresin capsicum.

persons participated. Their work characteristics are shown in table 1 , and are similar to those of first round participants.

The distribution of responses is shown in figure 1 . Using the a priori criterion for defining consensus, that is, $70 \%$ of participants indicating they strongly agreed or agreed that each topic was a priority, consensus was achieved for 45 of 71 topics. Using a less conservative definition of consensus, that is, $60 \%$, consensus was achieved for 60 topics. Using a more conservative definition of consensus, that is, $80 \%$, consensus was achieved for seven topics: diversion and alternatives to 


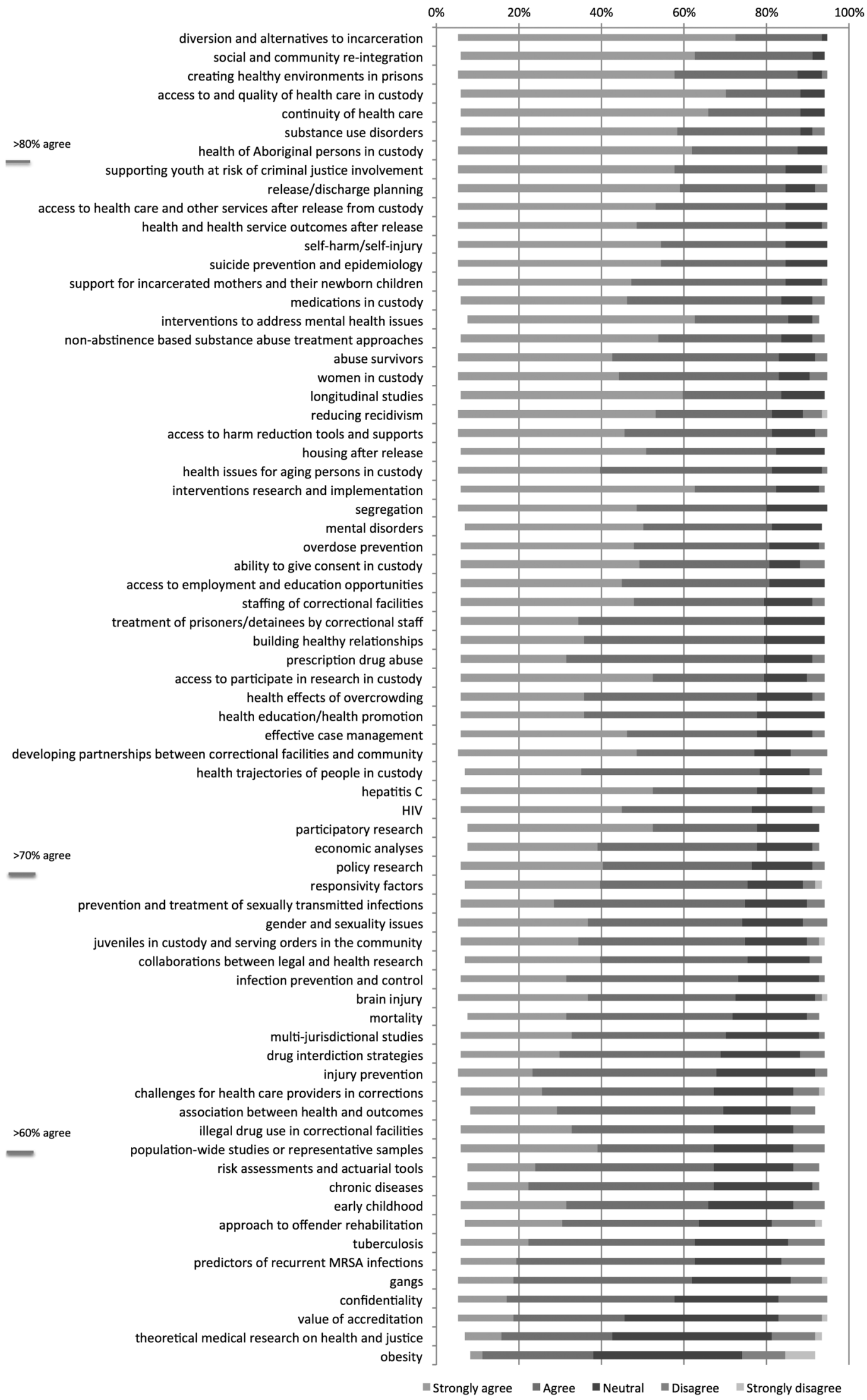

Figure 1 Per cent agreement by participants in a Delphi process in 2015 that each topic* is a priority for prison health research in Canada, $\uparrow \mathrm{N}=67$ participants. MRSA, methicillin-resistant Staphylococcus aureus. *Abbreviated titles for topics were used in this Figure. Full titles for each topic are provided in table 2; the full titles were used for the second round of the Delphi. †Sorted by the percent of participants who strongly agreed and agreed. 
incarceration, social and community re-integration, creating healthy environments in prisons, access to and quality of healthcare in custody, continuity of healthcare at the time of admission to and release from custody, substance use disorders and the health of Aboriginal persons in custody.

Based on the high level of consensus on most topics using the a priori criterion and the risk of a potentially low response rate in a third round (especially given the large number of suggested topics and the time it would take to consider each topic in light of other participants' ratings), the investigators decided to not conduct another round.

\section{DISCUSSION}

Through a consensus-building process, we have identified priority topics for research in prison health in Canada in the next 10 years. Most of the topics that were suggested by participants in the first round met our a priori criterion for consensus in the second round. The level of consensus was greater than $80 \%$ for seven topics, which were diversion from and alternatives to incarceration, healthcare and healthy environments in custody, community reintegration factors including social and community reintegration and continuity of healthcare, and more broadly, substance use disorders and the health of Aboriginal persons in custody.

The large number of topics identified as priorities is surprising, and may reflect the poor health of this population in Canada, ${ }^{12}$ the lack of research in prison health in Canada ${ }^{5}$ or a failure of dissemination and implementation of existing research from Canada and other jurisdictions. ${ }^{5}$ Any research on the priorities identified should proceed only after a comprehensive review of relevant research from Canada and other jurisdictions, and should build on existing promising or proven practices. ${ }^{7}$ That notwithstanding, many of the priorities identified in this study have been noted in other research that has looked broadly at the state of prison health research, ${ }^{46}$ providing external evidence that the results of this process are valid.

Strengths of this study include that there was a large number of participants with representation from diverse geographical areas, types of work and work settings; although a large majority of participants were primarily researchers and worked in university settings, this is likely appropriate for a study of stakeholders in prison health research and the high level of consensus for many topics indicates that persons across types of work and work settings agreed regarding their importance. We involved several investigators in collating topics from the first round to capture breadth and specificity while achieving a manageable number of topics to present in the second round.

Regarding potential limitations, the response rate was suboptimal, at $41.3 \%$ of those invited to participate in the first round and $48.9 \%$ of those invited to participate in the second round. We attempted to optimise participation by individually addressing each email and by sending reminders, and as noted, we achieved a sample that represented diverse groups. Some of the collated topics are broad and contain several components, for example 'access to and quality of healthcare, including mental healthcare, prenatal care, emergency care, preventive care, palliative care, dental care, geriatric medicine, pain management, contraception;' translating this priority and some other priorities into research plans will require further consideration and consultation. Stopping the Delphi process after the second round precluded us from determining whether stability had been achieved (ie, consistency of responses across rounds) ${ }^{11}$ regarding whether each topic was a priority and the relative priority of suggested topics, however, we decided to stop the process given the high level of consensus achieved for so many topics.

Derived through a systematic and inclusive methodology, the priorities identified in this study should inform the research agenda for prison health in Canada, and may also be relevant in other countries. Instead of relying on the perspective and knowledge of a single investigator or a small group of investigators, decisions about research should be determined based on the input of a diverse group of stakeholders, including patients and other affected populations. ${ }^{7}$ With this in mind, these priorities deserve attention by all stakeholders in prison health research in Canada.

The next steps to advancing research in this field should include creating a network of persons interested in prison health research, advocacy for research and for dedicated research funding and the development of programmes of research focused on some of the priorities identified in this study. Working on the most important research topics and ideally in collaboration, the prison health research community can take greater strides toward advancing the health and healthcare of this population.

Contributors FGK led the study, developed the protocol and wrote the article. AS, KEM and LP contributed to analyses. All authors contributed to the study design and to revising the manuscript, and approved the final manuscript.

Funding This study was funded by a Planning Grant from the Canadian Institutes for Health Research (grant number 316648). It was also supported by the Centre for Research on Inner City Health (CRICH), which is part of the Li Ka Shing Knowledge Institute of St. Michael's Hospital. Fiona Kouyoumdjian receives salary support from a Fellowship from the Canadian Institutes for Health Research. The opinions, results and conclusions are those of the authors and are independent from the funding, supporting and participating agencies.

Competing interests None declared.

Ethics approval St. Michael's Hospital Research Ethics Board.

Provenance and peer review Not commissioned; externally peer reviewed.

Data sharing statement No additional data are available.

Open Access This is an Open Access article distributed in accordance with the Creative Commons Attribution Non Commercial (CC BY-NC 4.0) license, which permits others to distribute, remix, adapt, build upon this work noncommercially, and license their derivative works on different terms, provided the original work is properly cited and the use is non-commercial. See: http:// creativecommons.org/licenses/by-nc/4.0/ 


\section{REFERENCES}

1. Walmsley R. World prison population list. 10th edn. London: King's College London International Centre for Prison Studies, 2013.

2. Kinner SA, Forsyth S, Williams G. Systematic review of record linkage studies of mortality in ex-prisoners: why (good) methods matter. Addiction 2013;108:38-49.

3. Perrault S. Admissions to adult correctional services in Canada, 2011/2012. 2014. http://www.statcan.gc.ca/pub/85-002-x/2014001/ article/11918-eng.htm-a2 (accessed 14 Dec 2014).

4. Fazel S, Baillargeon J. The health of prisoners. Lancet 2011;377:956-65.

5. Kouyoumdjian FG, Schuler A, Hwang SW, et al. Research on the health of people who experience detention or incarceration in Canada: a scoping review. BMC public health 2015;15:419.

6. Kouyoumdjian FG, Mclsaac KE, Liauw J, et al. A systematic review of randomized controlled trials of interventions to improve the health of persons during imprisonment and in the year after release. Am j Public Health 2015;105:e13-33.

7. Chalmers I, Bracken MB, Djulbegovic B, et al. How to increase value and reduce waste when research priorities are set. Lancet 2014;383:156-65.

8. Hasson F, Keeney S, McKenna H. Research guidelines for the Delphi survey technique. J Adv Nur 2000;32:1008-15.

9. Fink A, Kosecoff J, Chassin M, et al. Consensus methods: characteristics and guidelines for use. Am J Public Health 1984;74:979-83.

10. Jones J, Hunter D. Consensus methods for medical and health services research. BMJ 1995;311:376-80.

11. von der Gracht H. Consensus measurement in Delphi studies: review and implications for future quality assurance. Technological Forecasting and Soc Change 2012;79.

12. Kouyoumdjian F, Schuler A, Hwang SW, et al. The health status of prisoners in Canada: a narrative review. Canadian Family Physician. in press, 2015. 